\title{
ETHNOPHARMACOLOGICAL STUDY OF BRAIN OXIDATIVE STRESS IMPROVING POTENTIAL OF CURCUMIN IN INTOXICATED RATS
}

\author{
FATEN IBRAHIM EL-SAYED \\ Department of Pharmacology Faculty of Veterinary Medicine, Benha University, Egypt \\ Email: fatenibrahim73@yahoo.com
}

Received: 14 Jan 2021, Revised and Accepted: 19 Mar 2021

\begin{abstract}
Objective: The following study aimed to investigate the efficacy of curcumin at preventing amikacin neurotoxicity

Methods: Twenty-four male Wister albino rats were randomly divided into four groups including-G (1): control group includes six rats, they were administered $0.5 \mathrm{ml}$ of saline orally for 14 consecutive days. G (2): includes six rats; they were administered $200 \mathrm{mg} / \mathrm{kg}$ curcumin orally for 14 consecutive days. G (3): includes six rats, they were administered $300 \mathrm{mg} / \mathrm{kg}$ body weight/day of amikacin intraperitoneally for 14 consecutive days G (4): includes six rats, they were administered $200 \mathrm{mg} / \mathrm{kg}$ curcumin orally concurrently with $300 \mathrm{mg} / \mathrm{kg}$ body weight/day of amikacin. All animals were kept in the same conditions from feed, heat and humidity.

Results: According to the result obtained after sacrification of all animals after the end of $14 \mathrm{~d}$, Results revealed that amikacin at the dose rate of $300 \mathrm{mg} / \mathrm{kg} \mathrm{b}$. wt for $14 \mathrm{~d}$ induces significant changes in oxidative stress markers compared to the control group, a significant reduction in CAT. SOD. GSH $(1.51 \pm 0.16,77.00 \pm 0.73$ and $84.06 \pm 4.42)$ respectively compared to control $(3.63 \pm 0.11,98.48 \pm 0.18$ and $117.05 \pm 0.52)$ along with a significant increase in MDA activity (219.02 \pm 3.34$)$ compared to control group (180.42 \pm 0.19$)$, That indicate oxidative stress effect of it. On the beneficial side rats received amikacin $300 \mathrm{mg} / \mathrm{kg} \mathrm{B}$. wt I/p concurrently with $200 \mathrm{mg} / \mathrm{kg} \mathrm{b}$. wt curcumin for successive 14 day result in a significant increase in CAT. SOD. GSH $(2.23 \pm 0.09,92.00 \pm 0.26,102.25 \pm 1.71)$ and decrease in MDA concentration $(139.23 \pm 3.89)$ compared to amikacin treated group levels along with histopathological changes appear in brain tissue in the group treated with amikacin include nuclear pyknosis and degeneration in some neurons in the hippocampus, multiple focal eosinophilic plaque formation in the striatum also this results enhanced by activated caspase- 3 expression in the brain tissue following amikacin administration.
\end{abstract}

Conclusion: The present study proved that Oral administration of curcumin at the dose of $200 \mathrm{mg} / \mathrm{kg}$ for $14 \mathrm{~d}$ concurrently with amikacin significantly mitigates its neurotoxic and oxidative stress effects.

Keywords: Ethnopharmacology, Brain oxidative stress, Curcumin

(C) 2021 The Authors. Published by Innovare Academic Sciences Pvt Ltd. This is an open access article under the CC BY license (https://creativecommons.org/licenses/by/4.0/) DOI: https://dx.doi.org/10.22159/ijpps.2021v13i5.40778. Journal homepage: https://innovareacademics.in/journals/index.php/ijpps.

\section{INTRODUCTION}

Amikacin is a broad-spectrum aminoglycoside antibiotic derived from kanamycin and is highly effective against gram-negative organisms (including gentamycin-resistant strains) as well as a few gram-positive organisms [1]. It binds mainly to 30s ribosomes and interferes with the initiation of protein synthesis, block the translation of mRNA and prematurely terminate the protein synthesis. Like other aminoglycosides, it may cause nephrotoxicity, hepatotoxicity, ototoxicity, and neuromuscular block [2, 3].

Medicinal plants have been used by all civilizations since ancient times. Increasing risk of antibiotic side effects and resistance push scientists to pay attention to herbal extracts. One of them is Curcumin is one of the most important medicinal plants. it is a herbaceous plant belonging to the ginger family, it extracts from the rhizomes of plant of curcuma longa [4], it exhibits a variety of therapeutic properties, including antioxidant [5], antiapoptotic activities [6, 7]. It has a strong potency in inhibiting the generation of reactive oxygens species (ROS). Notably, curcumin can cross the blood-brain barrier suggesting a possible cause of neuroprotective effect [8]

So the objective of this study is to investigate the neurotoxic effect of amikacin on brain tissue and the neuroprotective role of curcumin.

\section{MATERIALS AND METHODS}

\section{Chemicals}

Amikacin (amikacin) was obtained as a patent preparation (Pharco company this is an I/V and I/M therapy. It is given by intraperitoneal injection at the dose rate of $100 \mathrm{mg} / \mathrm{kg}$ body weight/day previously described by [9]
Curcumin extract was obtained from National Research Center, Cairo, Egypt. It was used at a dose of $200 \mathrm{mg} / \mathrm{kg} \mathrm{b}$. wt orally for $14 \mathrm{~d}$ [10]

\section{Animals}

Twenty-four Wister albino rats weighing 200-250 gm were used in this investigation. They were obtained from the Animal House of the faculty of veterinary medicine, Benha University. They are fed on a normal rodent diet and apply water ad libtum. Rats were left for a week for acclimatization before the beginning of the experiment Rats were treated in accordance with the guidelines for animal experimentation of ethics review committee of faculty of veterinary medicine, Benha University Number (BUFVTM 010321)

\section{Experimental design}

Rats were divided into 4 groups.

Group (1): Served as a control group and it includes six rats; they were administered $0.5 \mathrm{ml}$ of saline orally for 14 consecutive days

Group (2): it includes six rats; they were administered $200 \mathrm{mg} / \mathrm{kg}$ curcumin orally for 14 consecutive days.

Group (3): it includes six rats; they were administered $300 \mathrm{mg} / \mathrm{kg}$ body weight/day of amikacin intraperitoneally for 14 consecutive days.

Group (4): it includes six rats; they were administered $200 \mathrm{mg} / \mathrm{kg}$ curcumin orally concurrently with $300 \mathrm{mg} / \mathrm{kg}$ body weight/day of amikacin intraperitoneally for 14 consecutive days.

\section{Evaluation of oxidative stress markers}

The brain was taken immediately after sacrification, washed in physiological saline. Half of the brain was preserved at-80 0c until 
preparation of tissue homogenate which is used for assessment of (MDA, CAT, GSH, and SOD) levels colorimetrically according to [11-14]

\section{Respectively}

\section{Histopathology and immunohistochemistry}

Another half of the brains were taken from the brain of rats in different groups and fixed in formalin solution $10 \%$ for twenty-four hours. .The obtained tissue sections were collected on glass slides, deparaffinized, and stained by hematoxylin and eosin stain for routine examination through the light microscope [15].

Another group of embedded paraffin sections was also prepared for immune detection of caspase 3 positive cells using an avidin-biotinperoxidase (ABC) methods [16]

\section{Statistical analysis}

First, all data are tested for normality and homogeneity then, oneway analysis of variance (ANOVA) used to determine the Statistical differences among groups followed by Duncan's multiple ranges as post hoc for making multiple comparisons using the Statistical Package for Social science Software (SPSS (25) software (SPSS Inc., Chicago, USA). The values were expressed as mean \pm standard error of studied groups.

\section{RESULTS}

Results showed that the administration of amikacin at the dose rate of $300 \mathrm{mg} / \mathrm{kg} \mathrm{b}$. wt for $14 \mathrm{~d}$ induces significant changes in oxidative stress markers compared to the control group, a significant reduction in CAT. SOD. GSH $(1.51 \pm 0.16,77.00 \pm 0.73$ and $84.06 \pm 4.42)$ respectively compared to control $(3.63 \pm 0.11,98.48 \pm 0.18$ and $117.05 \pm 0.52$ ) along with a significant increase in MDA activity $(219.02 \pm 3.34)$ compared to the control group $(180.42 \pm 0.19)$. On the beneficial side rats received amikacin $300 \mathrm{mg} / \mathrm{kg}$ B. wt $\mathrm{I} / \mathrm{p}$ concurrently with $200 \mathrm{mg} / \mathrm{kg} \mathrm{b}$. wt curcumin for successive 14day result in a significant increase in CAT. SOD. GSH $(2.23 \pm 0.09,92.00 \pm 0.26,102.25 \pm 1.71)$ and decrease in MDA concentration $(139.23 \pm 3.89)$ compared to amikacin treated group table 1.2, fig. 1.2.

\section{Histopathological finding}

Light micrograph of brain tissue found that no histopathological alteration recorded in both cerebral cortex, hippocampus, and striatum fig. 3 (A, B, C) whereas in the same of that from curcumin group fig. 3 (E, F, G) but they varied with that from amikacin treated rats that showing nuclear pyknosis and degeneration of some neurons of the hippocampus and multiple focal eosinophilic plaque formation in the striatum fig. $3(\mathrm{H}, \mathrm{I})$. On the other hands, in the case of sections from the amikacin and curcumin-treated group found a great protective effect of curcumin represented in no histopathological alteration in both cerebral cortex and hippocampus beside only some eosinophilic plagues formation in the striatum fig. $3(\mathrm{~J}, \mathrm{~K}, \mathrm{~L})$

\section{Immunohistochemical finding}

The immunohistochemical finding of Caspase 3, in brain tissue. Showed a change in caspase 3 expression after treatment with curcumin, amikacin, and curcumin with amikacin. The reaction in the brain is localized in the neuron. Immunostaining was performed using anti caspase 3 . The severity of the immunohistochemical reaction is depending on the density and distribution of dark brown coloration. Mild expression (+) was found in the amikacin group for caspase 3, while Nil expression (-) was found in other groups, table 3, fig. 4 (A, B, C, D).

Table 1: Effect of oral administration of curcumin at $200 \mathrm{mg} / \mathrm{kg}$ body weight for successive $14 \mathrm{~d}$ on MDA in amikacin (300 $\mathrm{mg} / \mathrm{kg} \mathrm{b}$. wt. b. wt) treated rats, $(\mathrm{n}=6)$

\begin{tabular}{ll}
\hline Groups & Mean \pm SE \\
\hline Control & $180.42 \pm 0.19^{\mathrm{b}}$ \\
Curcumin & $159.60 \pm 2.12^{\mathrm{c}}$ \\
Amikacin & $219.02 \pm 3.34^{\mathrm{a}}$ \\
Concurrent, & $139.23 \pm 3.89^{\mathrm{d}}$ \\
Amikacin+Curcumin & \\
\hline
\end{tabular}

Data are represented as (mean of 6 rats \pm SE). Mean values with different superscriped letters in the same column are significantly different at $(\mathrm{P}<0.05)$.

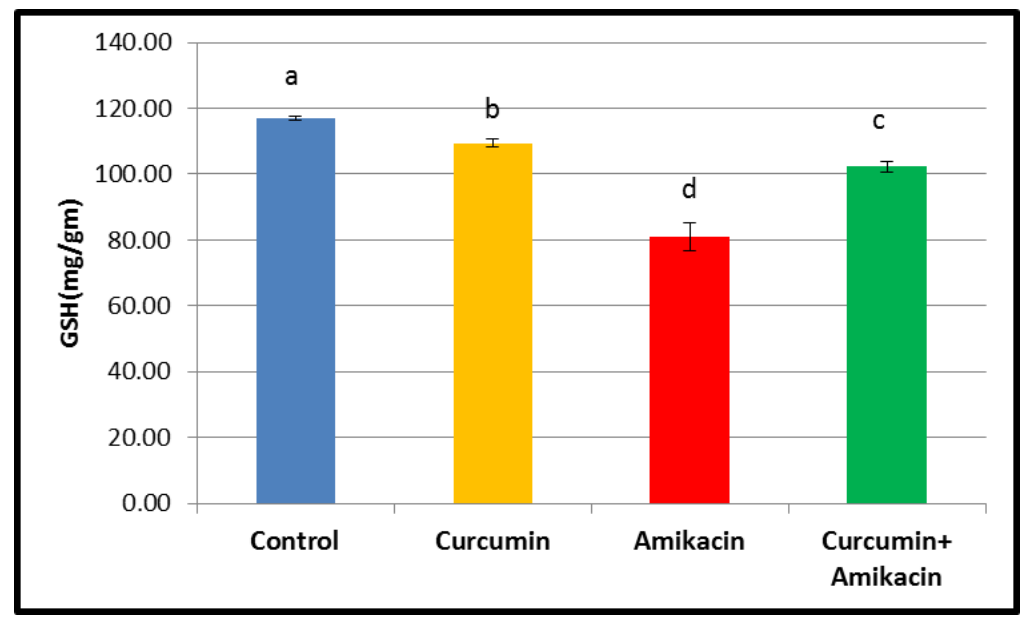

Fig. 1: Effect of oral administration of curcumin at $200 \mathrm{mg} / \mathrm{kg}$ body weight for successive $14 \mathrm{~d}$ on reduced Glutathione (GSH) concentration in amikacin $(300 \mathrm{mg} / \mathrm{kg}$ b. wt.) treated rats. $(\mathrm{n}=6)$. Data are represented as (mean of 6 rats $\pm S$. E) Mean values with different superscriped letters in the same column are significantly different at $(P<0.05)$

Table 2: Effect of oral administration of curcumin at $200 \mathrm{mg} / \mathrm{kg}$ body weight for successive $14 \mathrm{~d}$ on Superoxide dismutase (SOD) Concentration in amikacin $(300 \mathrm{mg} / \mathrm{kg}$ b. wt.) treated rats, $(\mathrm{n}=6)$

\begin{tabular}{ll}
\hline Groups & Mean \pm SE \\
\hline Control & $98.48 \pm 0.18^{\mathrm{a}}$ \\
Curcumin & $96.50 \pm 0.50^{\mathrm{b}}$ \\
Amikacin & $77.00 \pm 0.73^{\mathrm{d}}$ \\
Concurrent Amikacin+Curcumin & $92.00 \pm 0.26^{\mathrm{c}}$ \\
\hline
\end{tabular}

Data are represented as (mean of 6 rats \pm SE). Mean values with different superscripted letters in the same column are significantly different at $(\mathrm{P}<0.05)$ 


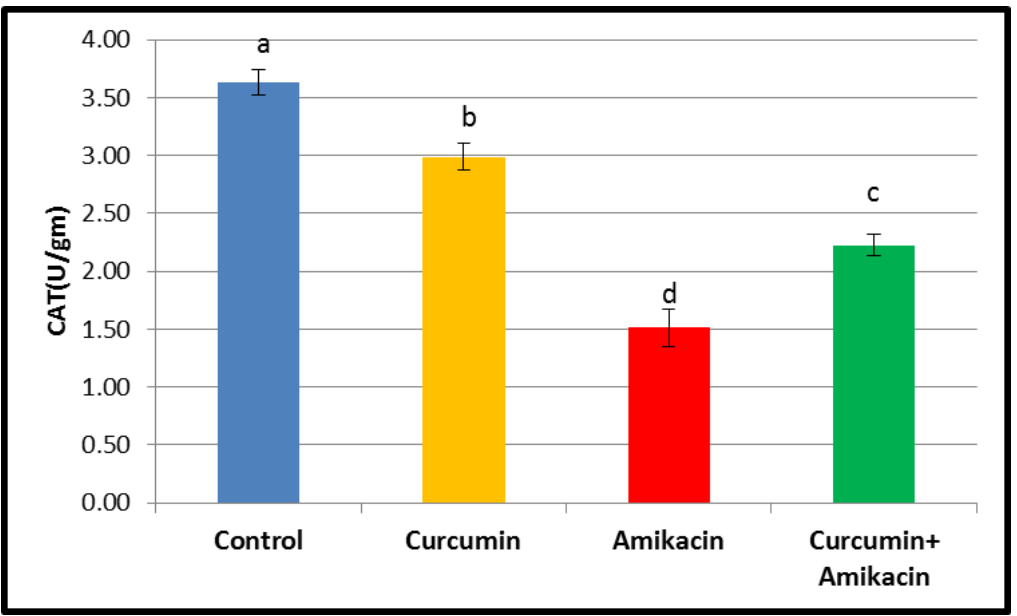

Fig. 2: Effect of oral administration of curcumin at $200 \mathrm{mg} / \mathrm{kg}$ body weight for successive $14 \mathrm{~d}$ on catalase (CAT) Concentration in amikacin $(300 \mathrm{mg} / \mathrm{kg}$ b. wt) treated rats. $(\mathrm{n}=6)$. Data are represented as (mean of 6 rats $\pm S E$ ). Mean values with different superscripted letters in the same column are significantly different at $(\mathrm{P}<0.05)$

Table 3: Effect of oral administration of curcumin at $200 \mathrm{mg} / \mathrm{kg}$ body weight for successive $14 \mathrm{~d}$ on caspase 3 expression of amikacin (300 $\mathrm{mg} / \mathrm{kg} \mathrm{b}$. wt) treated rat's brain

\begin{tabular}{ll}
\hline Groups & Caspase 3 \\
\hline Control & - \\
Curumine & - \\
Amikacin & ++ \\
Concurrent, Amikacin+Curcumin & -
\end{tabular}

+++ Sever++Moderate+Mild-Nil
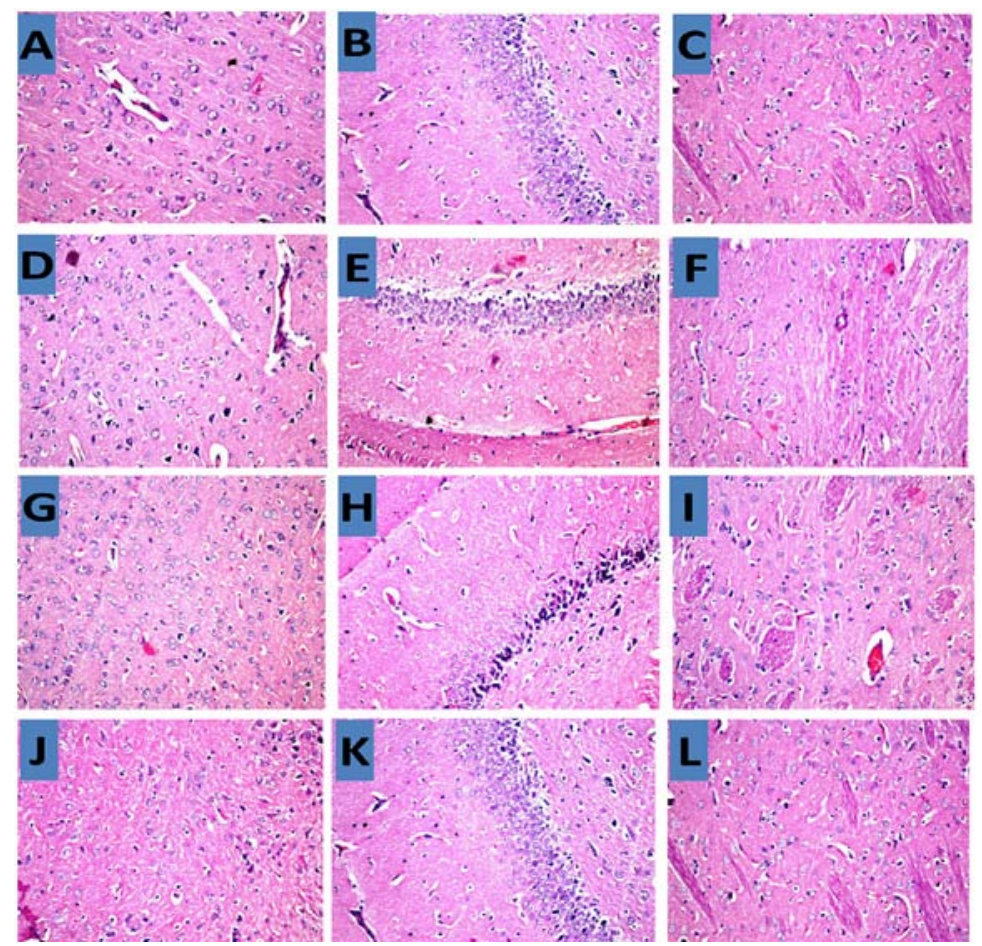

Fig. 3: Histopathological changes in brain tissue (A,B,C) cerebral cortex, hippocampus and striatum of brain of Control group found no histopathological ulteration, (D,E,F), cerebral cortex, hippocampus and striatum of brain of Curcumin treated group also found no histopathological ulteration, (G), cerebral cortex of brain of amikacin treated group also found no histopathological ulteration, (H) hippocampus of brain of amikacin treated group, nuclear pyknosis and degeneration were detected in some neurons, (I) multiple focal eosinophilic plagues formation were detected in striatum of brain of amikacin treated group, (J) cerebral cortex of concurrent group (Amikacin and curcumin) no histopathological alteration was detected, (K) some nuclear pyknosis and degeneration were detected in some neurons hippocampus of concurrent group (Amikacin and curcumin), (L), no histopathological alteration recorded in the striatum of the concurrent group (Amikacin and curcumin) immunohistochemistry 

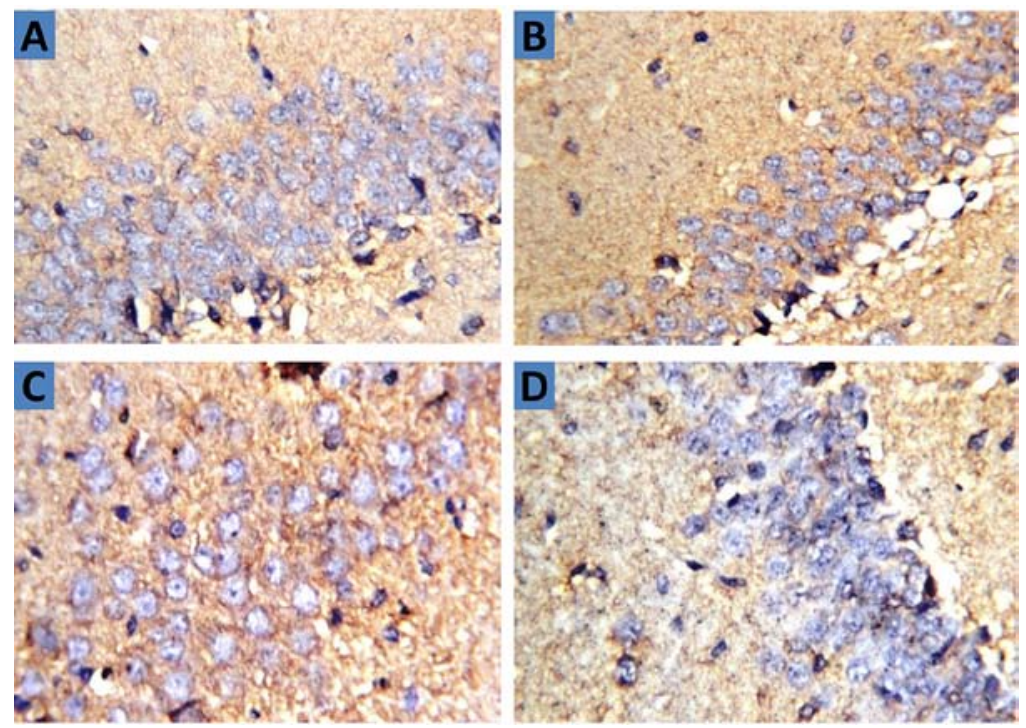

Fig. 4: Effect of oral administration of curcumin at $200 \mathrm{mg} / \mathrm{kg}$ body weight for successive $14 \mathrm{~d}$ on Caspase $3 \mathrm{expression}$ of amikacin (300 $\mathrm{mg} / \mathrm{kg}$ b. wt. b. wt treated rats brain. A: control group. B: curcumin group. C: Amikacin group. D: concurrent group. The severity of the immunohistochemical reaction is depending on the density and distribution of brown dark coloration. Mild expression (+) was found in the amikacin group (C) for caspase 3, while nil expression (-) was found in other groups (A, B, D)

\section{DISCUSSION}

A great rule of aminoglycoside in the treatment of gram-negative bacteria increases the interest in its usage but the favor of neurotoxicity restricts its use. So improvement of neurotoxicity will open the window for using a higher dose of amikacin; beside that the fact that Curcumin has antioxidant and anti-apoptotic activity $[5,7$, 17], that induce neuroprotective effects $[18,19]$, This study was conducted to assess the potential protective effect of curcumin against amikacin induced neurotoxicity.

Cells contain several antioxidants to prevent and repair cell damage CAT enzymatic antioxidant catalase $\mathrm{H} 202$ to water and oxygen [20]. GSH is a cofactor for several enzymes, it plays a role in detoxifying hydrogen peroxidase and lipid peroxidase through its action on glutathione peroxidase GSH px it protects the cell against apoptosis by interacting with the pro-apoptotic signal pathway [21]. MDA is a biomarker of oxidative stress; the degree of lipid peroxidation can be estimated by the amount of malondialdehyde in tissue [22]. Reactive oxygen species degrade polyunsaturated lipids forming malondialdehyde [23]. This component is a reactive aldehyde and is one of the many reactive electrophile species that cause toxic stress in cells [24]. Superoxide dismutase (SOD) is reasonable for the catalytic decomposition of superoxide anion into oxygen and hydrogen peroxide [25].

Curcumin has neuroprotective characteristics. It has antioxidant activity anti-inflammatory and anti-protein aggregate activity [26].

The imbalance between oxidants and antioxidants in favor of oxidants is referred to as oxidative stress [27]. Oxidative stress plays a great role in many diseases and also in various types of druginduced liver, heart brain, and renal toxicity [28, 29].

During investigation revealed that intraperitoneal injection of amikacin with a dose rate of $300 \mathrm{mg} / \mathrm{kg} \mathrm{b}$. wt. once daily for $14 \mathrm{~d}$ produce oxidative stress in brain tissue which is evidenced with significantly lowered antioxidant activity (CAT, GSH, SOD) along with increase free radical-mediated damage as evidence of increased MDA level. This result was in harmony with that investigated by [30] in the liver and kidney. Interestingly, our results indicated that administration of $200 \mathrm{mg} / \mathrm{kg}$ b,wt curcumin concurrently with amikacin for $14 \mathrm{~d}$ protect brain tissues against amikacin induced oxidative stress via improvement of the antioxidant status (CAT, GSH, SOD) and consequently reduced lipid peroxidation (MDA)concentration this amelioration of oxidant/antioxidant status of brain tissue by curcumin could be attributed to direct reduction of ROS generation and release [31], scavenging of the free radicals and subsequent inhibition of oxygenation reaction as curcumin has been reported to be a good antioxidant and free radical scavenger, inhibit lipid peroxidation [5]. Curcumin may reduce lipid peroxidation by enhancing the activities of antioxidant enzymes and GSH levels as they play an essential role in lipid peroxidation regulation $[32,33]$. Together, these mechanisms may explain, at least in part, the cytoprotective effect of curcumin which confirm by the improvement of the brain structure of sections from the concurrent group.

Likewise, curcumin administration to rats at an oral dose of 200 $\mathrm{mg} / \mathrm{kg}$ b. et for $10 \mathrm{~d}$ significantly increased SOD and GSH levels as well as histopathological findings of gentamycin-treated rats [10].

Apoptosis is a physiological process for removing unwanted cells during development and for maintaining tissue homeostasis [34]. Deregulation of this process causes several disorders like neurodegenerative disorder [35]. Caspases are crucial mediators of apoptosis among them: Caspase 3 is frequently activated death protease, catalyzing the specific cleavage of many key cellular proteins [36] and lead to DNA breakdown, which is one of the characteristic cellular changes of apoptosis [37].

Fourthinatly, In the present study curcumin, could ameliorate the effect of amikacin on the expression level of caspase 3 in the concurrent group. these results in mat be caused by the ability of curcumin to prevent GSH decrease, thus protecting the cell from caspase 3 activation and DNA fragmentation [38]. On the same line, [39] concluded downregulation of caspase 3 expression, as well as elevation of intracellular GSH level in manganese exposed microglial cells.

\section{CONCLUSION}

The present study proved that, Oral administration of curcumin at the dose of $200 \mathrm{mg} / \mathrm{kg}$ for $14 \mathrm{~d}$ concurrently with amikacin result imporvment to antioxidant activity and it is illustrated by significant increase in CAT. SOD. GSH and decrease in MDA concentration compared to amikacin intoxicated group levels along with a great protective effect of curcumin represented in no histopathological alteration in both cerebral cortex and hippocampus beside only some eosinophilic plagues formation in the striatum.

\section{FUNDING}

Nil

\section{AUTHORS CONTRIBUTIONS}

All the authors have contributed equally. 


\section{CONFLICT OF INTERESTS}

There is no conflict of interest

\section{REFERANCES}

1. Cunha BA. Aminoglycosides: current role in antimicrobial therapy. Pharmacotherapy 1988;8:334-50.

2. Gilbert DN, Mandell GL, Bennett JE, Dolin R. Aminoglycosides in principles and practice of infectious diseases 2000;5:307-36.

3. Cipullo JP, Burdmann EP. Aminoglycoside nephrotoxicity. Braz J Cardiovasc Sur 2006;21:444-52.

4. Deliana NI R, Melva I, Vivian S. Effects of curcumin and nanocurcumin on cisplatin-induced nephrotoxicity in rat: copper transporter 1 and organic cation transporter 2 as drug. Transporters Int J Appl Pharm 2018;1:172.

5. Ak T, Gulcin I. Antioxidant and redical scavening properties of curcumin. Chem Boil Interact 2008;174:27-28.

6. Chan WH, Wu HJ. Antiopoptotic effects of curcumin on photosensitized human epidermal carcinoma A431 cells. J Cell Biochem 2004;92:200-12.

7. Aktas C, Kanter M, Erboga M, Oztrul S. Antiopoptotic effects of curcumin on cadmium induced opoptosis in rat testes. Toxicol Ind Health 2012;28:122-30

8. Ghosh S, Banerjee S, Sil PC. The beneficial role of curcumin on inflammation, diabetes and neurodegenerative disease: a recent update. Food Chem Toxicol 2015;83:111-24.

9. Batoo AS, Hussain K, Singh R, Sultana M, Sharma N, Nabi B, et al. Biochemical and oxidative alterations induced by acute amikacin toxicity in albino wistar rats. J Anim Res 2018;8:40710.

10. Ali BH, AlWabel N, Mahmoud O, Mousa HM, Hashad M Curcumin has a palliative action on gentamicin-induced nephrotoxicity in rats. Fundam Clin Pharmacol 2005;19:473-7.

11. Ohkawa H, Ohishi N, Yagi K. Assay for lipid peroxides in animal tissues by thiobarbituric acid reaction. Anal Biochem 1979;95:351-8.

12. Aebi H. Catalase in vitro. Methods Enzymol 1984;105:121-6.

13. Beutler E, Duron O, Kelly BM. Improved method for the determination of blood glutathione. J Lab Clin Med 1963;61:882-8.

14. Nishikimi M, Roa N, Yogi K. Measurement of superoxide dismutase Biochem Biophys Res Common 1972;46:849-54.

15. Banchroft JD, Stevens A, Turner DR. Theory and practice of histological techniques. Fourth Ed. Churchil Livingstone, New York: London, San Francisco, Tokyo; 1996.

16. Mohamed AA, Galal AA, Elewa YH. Comparative protective effects of royal jelly and cod liver oil against neurotoxic impact of tartrzaine on male rats pups brain. Acta histochemica 2015;117:649-58.

17. Hanai H, Sugmioto K. Curcumin has bright prosoects for the treatment of inflammatory bowl diseases. Cur Pharm Des 2009;15:2087-94.

18. Uger S, Ulu R, Dogukan A, Gurel A, Yigit IP, Gozel N, et al:: The renoprotective effect of curcumin in cisplatin induced nephrotoxicity. Ren Fail 2015;37:332-6.

19. Khatri DK, Juvekar AR. Neuroprotective effect of curcumin as evinced by abrogation of rotenone-induced motor deficits, oxidative and mitochondrial dysfunctions in mouse model of Parkinson's disease. Pharmacol Biochem Behav 2016;150:39-47.

20. Weydert CG, Cullen JJ: Measurement of superoxide dismutase, catalase and glutathione peroxidase in cultured cells and tissues. Natural Protocola 2010;5:51-66
21. Masellia RM, Dibendetto R, Vari R, Filesi CM, Giovannini C. Noval mechanism of natural antioxidant compounant in biological system: involvement of glutathione and glutathione related enzymes. J Nut Biochem 2005;16:577-86.

22. Davey MW, Stals E, Panis B, Keulemans J, Swennen RL. Highthroughput determination of malondialdehyde in plant tissues. Anal Biochem 2005;347:201-7.

23. Pryor WA, Stanley JP. Letter: a suggested mechanism for the production of malonaldehyde during the autoxidation of polyunsaturated fatty acids. Non enzymatic production of prostaglandin end peroxides during autoxidation. J Org Chem 1975;40:3615-7.

24. Farmer EE, Davoine C. Reactive electrophile species. Curr Opin Plant Biol 2007;10:380-6.

25. Zelko IN, Mariani TJ, Folz RJ. Superoxide dismutase multigene family: a comparison of the CuZn-SOD (SOD1), Mn-SOD (SOD2), and EC-SOD (SOD3) gene structures, evolution, and expression. Free Radical Biol Med 2002;33:337-49.

26. Cole GM, Teter B, Frautschy SA. Neuroprotective effects of curcumin. Adv Exp Med Biol 2007;595:197-212.

27. Birben E, Sahiner UM, Sackesen C, Erzurum S, Kalayci O Oxidative stress and antioxidant defense. World Allergy Organ J 2012;5:9-19.

28. Deavall DG, Martin EA, Horner JM, Roberts R. Drug-induced oxidative stress and toxicity. J Toxicol 2012;2012:645460.

29. Pereira CV, Nadanaciva S, Oliveira PJ, Will Y. The contribution of oxidative stress to drug-induced organ toxicity and its detection in vitro and in vivo. Expet Opin Drug Metabol Toxicol 2012;8:219-37.

30. Singhal M, Prajapati B. In vivo evaluation of aminoglycoside induced nephrotoxicity and hepatotoxicity in albino rats. Pharmacologyonline 2011;2:451-7.

31. Joe B, lokesh BR. Role of capacicum, curcumine and dietry n-3 fatty acid in lowering the generation of reactive oxygen species in rat peritoneal macrophage. Biochim Biophys Acta 1994;1224:255-63.

32. Susan M, Rao MN. Induction of glutathione S-transferase activity by curcumin in mice. Arzneimittel Forschung 1992;42:962-4.

33. Jagetia GC, Rajanikant GK. Curcumin stimulates the antioxidant mechanisms in Mouse skin exposed to fractionated $\gamma$-irradiation. Antioxidants 2015;4:25-41.

34. Mendez A, Nava Ruiz C, Juarez D, Rodriguz E, Gomez PY. Oxidative stress assoiated with neuroopoptosis in experimental model of epilepsy. Oxid Med Cell Longev 2014. DOI:10.1155/2014/293689.

35. Agostinia M, Tucci P, Melino G. Cell death pathology: perspective for human diseases. Biochem Biophys Res Commun 2011;414:451-5.

36. Porter AG, Janick RU. Emerging roles of caspase 3 in opoptosis. Cell Death Differ 1999;6:99-104.

37. Faubel S, Ljubanovic D, Reznikov L, Somerset H, Dinarello CA Edelstein CL. Caspase-1-deficient mice are protected against cisplatin-induced apoptosis and acute tubular necrosis. Kidney Int 2004;66:2202-13.

38. Piwocka K, Jargua E, Skierski J, Gradaska L, Sikora E. Effect of glutathione depletion on caspase 3 independent opoptosis pathway induced by curcumin in jurkat cell. Free Radical Biol Med 2001;31:670-8.

39. Park E, Chun HS. Protective effect of curcumin on manganese induced BV-2 microglial cell death. Biol Pharm Bull 2017;40:1275-81. 